\section{Cardiopulmonary Arrest After Severe Anaphylactic Reaction to Second Infusion of Infliximab in a Patient with Ankylosing Spondylitis}

To the Editor:

Infliximab is an anti-tumor necrosis factor- $\alpha$ (TNF- $\alpha$ ) chimeric monoclonal antibody widely used to treat chronic inflammatory diseases such as rheumatoid arthritis, Crohn's disease, ankylosing spondylitis (AS), and psoriasis. Infusion reaction to infliximab occurs in approximately $5 \%$ of patients ${ }^{1}$. Although severe anaphylactic reactions including hypotension, arrhythmia, and bronchospasm have been reported, there is no report of cardiopulmonary arrest strongly connected with the infliximab infusion. We describe a patient with AS who developed cardiopulmonary arrest after an anaphylactic reaction to the second infliximab infusion.

A 37-year-old man with no history of allergy or coronary artery event received infliximab infusion for AS at our hospital. His symptoms were refractory to nonsteroidal antiinflammatory drugs, and he had been treated with salazosulfapyridine ( $1000 \mathrm{mg} /$ day) alone for 2 years. One year before starting infliximab infusion, his electrocardiogram (ECG) showed no abnormality. In prescreening ultrasound cardiogram wall motion and aortic valve function were normal. The first infusion $(5 \mathrm{mg} / \mathrm{kg}$, total dose $275 \mathrm{mg}$ ) did not cause any adverse reactions. After canceling 2 appointments, he received the second infusion 12 weeks after the first treatment, without premedication. Three minutes after starting the infusion, he rapidly developed dyspnea and skin redness. Infusion was immediately stopped. He lost consciousness and developed cardiopulmonary arrest. The ECG monitor showed ventricular tachycardia (VT). Within 2 minutes, he recovered to sinus rhythm without use of a defibrillator. He was treated for anaphylaxis with epinephrine, methylprednisolone, chlorpheniramine maleate, and famotidine. In the emergency room, he was intubated and continuous vasopressor was administered.

Upper airway symptoms and skin redness improved daily. Seventy hours after the event, he developed VT that resolved spontaneously. ECG showed prolonged QT interval and ST-T depression in V1-6. There were no abnormalities in cardiac enzymes or coronary arteriographic or electrophysiological findings. Coronary artery spasm was suspected as the cause of VT, while prolonged QT may have been associated with H1/2 blocker administration. Anaphylaxis has been identified as a cause of coronary artery spasm $^{2,3}$. After treatment for ventilator-associated pneumonia, he was discharged on Day 17 without sequelae.

The recommended timing of infliximab infusion is 0,2 , and 6 weeks, followed by every 8 weeks. Although the risk of infusion reaction to infliximab increases when administered years after the previous infusions ${ }^{4}$, we doubt whether the 12-week interval between first and second infusions in our patient was associated with the severe anaphylactic reaction. This interval is not markedly different from the standard interval of 8 weeks, and usually a 12-week interval after fourth infusion results in no significant increase of infusion reaction. Therefore, this case indicates that life-threatening anaphylactic reactions to infliximab may not be predictable based on the laboratory examinations currently performed. The formation of human anti-chimeric antibodies (HACA), particularly $\operatorname{IgE}$ isotype, has been shown to relate to hypersensitivity to infliximab infusion ${ }^{5,6}$. However, examination of anti-infliximab $\mathrm{IgG}$ and $\mathrm{IgE}$ antibodies is not available for routine clinical practice. Although history of allergy sometimes gives clues to the allergic reaction, this case had no history of allergy, and serum $\operatorname{IgE}$ in this patient was only $11 \mathrm{IU} / \mathrm{ml}$. Generalized premedication could be a strategy to reduce the risk of infusion reaction, but steroid-based premedication would not decrease the incidence or severity of infusion reaction to infliximab ${ }^{7}$.

Our report emphasizes the potential risk of unpredictable severe anaphylactic reaction to infliximab. A more sophisticated algorithm and examination may be required in order to predict infusion reaction to biologics.

HARUKA MIKI, MD; AKIKO OKAMOTO, MD, PhD; KAZUYOSHI ISHIGAKI, MD; OH SASAKI, MD; SHUJI SUMITOMO, MD, PhD; KEISHI FUJIO, MD, PhD; KAZUHIKO YAMAMOTO, MD, PhD, Department of Allergy and Rheumatology, Graduate School of Medicine, University of Tokyo, Tokyo, Japan. Address correspondence to Dr. Fujio; E-mail: kfujio-tky@umin.ac.jp

We thank Dr. Mihoko Shibuya, Dr. Miho Oshima, Dr. Hiroaki Harada, and Dr. Hiroko Kanda from the Department of Allergy and Rheumatology for their diagnosis and assistance with this report.

\section{REFERENCES}

1. Cheifetz A, Smedley M, Martins S, Reiter M, Leone G, Mayer L. The incidence and management of infusion reactions to infliximab: a large center experience. Am J Gastroenterol 2003;98:1313-24.

2. Fujita Y, Chikamitsu M, Toriumi T, Endoh S, Sari A. An anaphylactic reaction possibly associated with an intraoperative coronary spasm during general anesthesia. J Clin Anesth 2001;13:221-6.

3. Conraads VMA, Jorens PG, Ebo DG, Clays MH, Bosmans JM, Vrints CJ. Coronary artery spasm complicating anaphylaxis secondary to skin disinfectant. Chest 1998;113:1417-9.

4. Sugiura F, Kojima T, Oba M, Tsuchiya H, Ishiguro N. Anaphylactic reaction to infliximab in two rheumatoid arthritis patients who had previous infliximab and resumed. Mod Rheumatol 2005;15:201-3.

5. Cheifetz A, Mayer L. Monoclonal antibodies, immunogenicity and associated infusion reactions. Mt Sinai J Med 2005;72:250-6.

6. Vultaggio A, Matucci A, Nencini F, Pratesi S, Parronchi P, Rossi O, et al. Anti-infliximab $\mathrm{IgE}$ and non-IgE antibodies and induction of infusion-related severe anaphylactic reactions. Allergy 2009;65:657-61.

7. Sany J, Kaiser MJ, Jorgensen C, Trape G. Study of the tolerance of infliximab infusions with or without betamethasone premedication in patients with active rheumatoid arthritis. Ann Rheumatol 2005;64:1647-9.

J Rheumatol 2011;38:6; doi:10.3899/jrheum.110076 